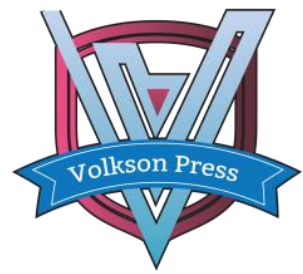

Contents List available at VOLKSON PRESS

Economics \& Management Innovations(EMI)

DOI : http://doi.org/10.26480/icemi.01.2017.197.199

\title{
A Study on Team Effectiveness for Entrepreneurism and Employee Creativity: Learning Goal Orientation as Moderator Variable
}

\author{
Wen-Chuan WU, Ji QI, Xiang YOU, An-Jin SHIE* \\ Ming Yang China-ASEAN International College, Dhurakij Pundit University, Thailand \\ *mingyang116@163.com
}

This is an open access article distributed under the Creative Commons Attribution License, which permits unrestricted use, distribution, and reproduction in any medium, provided the original work is properly cited.

\section{ARTICLE DETAILS}

\section{Article History:}

Received 02 october 2017

Accepted 06 october 2017

Available online 11 october 2017

Keywords:

Entrepreneurism, Employee

Creativity, Team Effectiveness,

Learning Goal Orientation.

\section{ABSTRACT}

The purpose of this study is to explore the causal relationships among entrepreneurism, employee creativity and team effectiveness. It has been suggested that employee creativity has a moderate effect in the model, but learning goal orientation used as an intervention variable to explore the correlating effects on entrepreneurism, employee creativity and team effectiveness, has much greater significance. First of all, this study is based on literature reviews to develop a research model and questionnaire. Then, we collected 550 samples, used narrative statistical analysis, reliability and validity analysis and linear regression analysis in the statistical analysis. The results show that entrepreneurism has no effect on employee creativity. Employee creativity has a positive impact on the team. However, motivational interrelationships are not affected. Learning goal orientation not only has a correlating effect on entrepreneurism and employee creativity, but also between employee creativity and team effectiveness. The ideas and benefits in this study are further discussed.

\section{Introduction}

Schumpeter (2000) mentioned that entrepreneurism is the driving force of product innovation, and is the key to the operation of promoting the reform process. At the same time, team interaction is an important player in improving the entrepreneurism of the unit. When the group promotes the exchange of team members, unrestrained interaction can achieve free information exchange, these entrepreneurs can lead the team members to produce more innovative activities and innovative ability (Dong et al., 2017). Entrepreneurism plays a very important role in promoting corporate innovation and productivity. Many scholars also believe that entrepreneurism has always played an important role in organizational and economic growth (García et al., 2017; Trong Tuan, 2017). However, the previous literature on entrepreneurism lacks a discussion of the relationships between employee creativity and team effectiveness. Therefore, the purpose of this study is to summarize the relationship among entrepreneurism, employee creativity and team effectiveness, to develop a research model, to further explore the relationships among entrepreneurism, employee creativity and team effectiveness, and to validate learning goal orientation to entrepreneurism, and whether learning goal orientation has moderator effect on employee creativity and team effectiveness.

\section{Research Design and Methodology}

This study summarizes the relevant literature and variables to build the research framework as shown in Figure 1. The variables include: entrepreneurism, employee creativity, team effectiveness and learning goal orientation. This study focuses on the relationship among entrepreneurism, employee creativity and team effectiveness. At the organizational level, it explores whether entrepreneurism, employee creativity and team effectiveness interact with each other; and explores whether employee creativity, entrepreneurism and team effectiveness have an impact. Based on the study motives, the study proposed the followinghypothesis:

H1: Entrepreneurism will positively affect employee creativity;

H2: Employee creativity will positively affect team effectiveness;

H3: Learning goal orientation will improve entrepreneurism in employee creativity;
H4: Learning goal orientation will improve employee creativity in team effectiveness; H5: Employee creativity has a mediating role on entrepreneurism and team effectiveness.

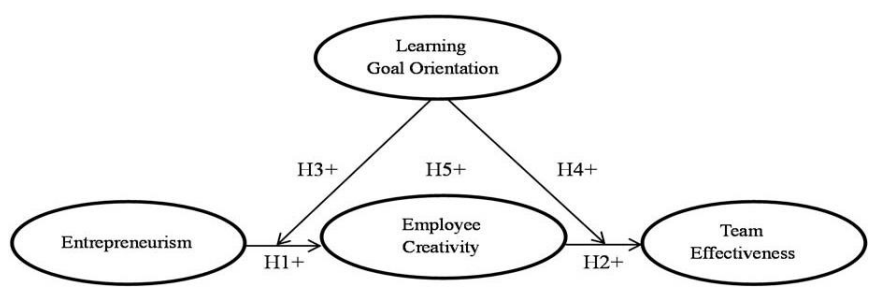

Figure 1. Research Model

First of all, this study proposed a research model and a questionnaire by integrating Miao et al. (2017)'s entrepreneurism, Dong et al. (2017) 's employee creativity, Jiang and Gu (2016)'s team effectiveness and Braekkan and Tunheim (2013)'s learning goal orientation. Secondly, this study used questionnaires to collect the data; the sampling method was to use internet network sample distribution, organize network questionnaire systems and establish e-questionnaire files, the platform utilized in the process being "WeChat". Finally, the questionnaire was distributed from June 1 to August 31, 2016, and 550 questionnaires were distributed. We then received 550 back, meaning the recovery rate was $100 \%$. Data analysis tools were analyzed using SPSS 22.0, using Cronbach's Alpha for the four variables of the questionnaire for reliability testing, and using regression analysis to validate the hypothesis of the proposed mode.

\section{Data Analysis and Discussion}

\subsection{Reliability and Validity Analysis}

Cronbach's alpha was used to analyze the reliability of the four variables of the questionnaire. Among them, the entrepreneurism was 0.87 , the employee creativity was 0.80 , the team effectiveness was 0.87 , the learning goal orientation was 0.87 , Showing that the dimensions of reliability indicators are greater than 0.7 , indicating that the reliability of the test to achieve the standard. In addition, the validity test of this study is based on the content validity test. Since the questionnaire prepared in 
this study is based on the research of the relevant scholars, it is logical and effective. Therefore, it can be considered that the questionnaire and scale have good content validity.

\subsection{Regression Analysis}

The regression analysis was used to validate the assumptions of the research framework. First, we validate the analysis of the employee creativity. The R-squared of the regression equation is 0.00 , and the $\mathrm{F}$ statistic of the regression equation is 2.020 , which significance is 0.16 , the significance is greater than 0.05 , indicating that the regression equation model is not significant and the fitting condition is not good. According to the regression coefficient table, it shows that the regression coefficient of entrepreneurism is 0.09 ; its significance is 0.16 , greater than 0.05 , indicating that the regression coefficient is not significant, entrepreneurism has no significant effect on employee creativity, and the result does not support $\mathrm{H} 1$.

The empirical analysis of the impact of employee creativity on team effectiveness is 0.63 for the regression equation model, the $\mathrm{F}$ statistic of the regression equation is 655.05 , the significance is 0.00 , less than 0.05 , indicating that the regression equation model is significant, The fitting condition is very good, and the model has some statistical significance. The regression coefficient of employee creativity is 0.70 , its significance is 0.00 , less than 0.05 , indicating that the regression coefficient is significant, employee creativity has a significant positive effect on team effectiveness, and the result does support $\mathrm{H} 2$.

\subsection{Moderator Effects of Learning Goal Orientation}

Firstly, the variable setting in this study includes: 'entrepreneurism' as an independent variable, 'employee creativity' as a dependent variable, and 'learning goal orientation' as moderator variable. Therefore, the regression model of the R-squared increased by 0.01 , the increase in the $\mathrm{R}$-squared of the significance is 0.03 , less than 0.05 , indicating the existence of moderate effects. According to the regression coefficient table, it shows that the regression coefficient of entrepreneurism and learning goal orientation cross-item is 0.23 , and its significance is 0.03 , less than 0.05 , which indicates that the cross-term regression coefficient is significant. That is, in the context of learning goal orientation as a moderator variable, the entrepreneurism has a positive effect on employee creativity, so the result is to support $\mathrm{H} 3$.

'Learning goal orientation' is a moderator variable to 'employee creativity' and team effectiveness. In this study, 'employee creativity' is taken as the independent variable and the 'team effectiveness' as the dependent variable. After adding the moderator variable, the regression model R-squared is increased by 0.02 , the increase in the R-squared of the significance is 0.00 , less than 0.05 , indicating the existence of moderate effects. According to the regression coefficient table, it shows that the regression coefficient of employee creativity and learning goal orientation cross is 0.20 , and its significance is 0.00 , less than 0.05 , indicating that the cross-term regression coefficient is significant. That is, in the context of learning goal orientation as a moderator variable, employee creativity has a positive effect on team potency, so the result is to support $\mathrm{H} 4$.

\subsection{Analysis of Employee Creativity Mediating Effect}

The variable settings in this study includes: 'entrepreneurism' as an independent variable, 'employee creativity' as a mediator variable, 'team effectiveness' as a dependent variable. We conducted regression analysis. The results illustrated that the coefficient is 0.220 , the significance is 0.000 , less than 0.05 , and the regression coefficient is significant. In the second step, the regression coefficient of the independent variable is 0.091 , the significance is 0.156 , and the regression coefficient is not significant. It is found that the creativity of employees in entrepreneurism and team effectiveness does not have a mediating effect, so the result is not to support H5.

\section{Discussion}

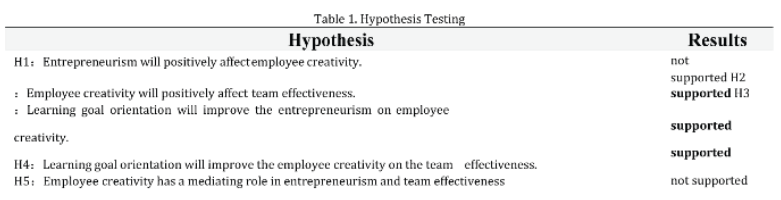

The regression analysis in Table 1 shows that significance is 0.16 , greater than 0.05 , indicating that $\mathrm{H} 1$ entrepreneurism positively affecting employee creativity, is not established. However, Brown et al. (2001) mentioned that entrepreneurial spirit brings spiritual support to employees, motivating employees' intrinsic motivation and responsibility, which is one of the conditions for employee innovation, which means that entrepreneurism leads to employee innovation and provides strong support to prove that the entrepreneurism has a positive impact on employee innovation. It is clear that this research theory is contrary to H1. The reason may be that entrepreneurism, when impacting on the creativity of employees, does not necessarily have a positive impact.

Employees offer new and promising ideas, and effectively solve the existing problems within the organization, that is employee creativity, and team effectiveness is a measure of team performance

and quality of life (Farmer et al., 2003). At the same time, Tamer Cavusgil et al. (2003) suggested that creativity is a key factor in achieving team effectiveness, so team effectiveness will be better when the organization's employees are more creative. This conclusion is consistent with this study assuming that $\mathbf{H} \mathbf{2}$ is that employee creativity that will positively affect team effectiveness. Ames and Archer (1988) also said that highly-creative employees will use more effective learning strategies; better understand the thinking of business leaders. This conclusion is consistent with the hypothesis of $\mathbf{H 3}$ and learning goal orientation will improve the moderator effect of entrepreneurism on employee creativity. Midgley et al. (2001) argued that in a business, learning goal orientation has a significant degree of help for team effectiveness. This conclusion is consistent with this study assuming that H4 is consistent, learning goal orientation will improve employee creativity on team effectiveness.

\section{Conclusions andSuggestions}

Employee creativity has a positive impact on team effectiveness. However, the mediation effect does not hold. Which joins the learning goal orientation as a moderator, both of its two relations have an impact, and has improved, so the moderator effect is established. The study shows that learning goal orientation as a moderator variable will improve the entrepreneurism on employee creativity, and improves employee creativity on team effectiveness. That is, the higher the learning goal orientation, the higher the positive impact of entrepreneurism on employee creativity, for the same reason, the higher the learning goal orientation, the higher the positive impact of employee creativity on team effectiveness. Therefore, the enterprise to enhance entrepreneurism and learning goal orientation, more employee creativity will mean team effectiveness will be higher. As this study in the course of the research process, did not control other factors, such as employee personal characteristics, and leader support, it is recommended in any follow-up study the above factors could be used as a research variable to do further analysis to expand content, and enrich thetheory.

\section{Reference}

[1] Ames, C. \& Archer, J. 1988. Achievement goals in the classroom: Students' learning strategies and motivation processes. Journal of Educational Psychology, 80(3): 260.

[2] Braekkan, K. F. \& Tunheim, K. A. 2013. Psychological contracts, careerism, and goal orientations. International Journal of Organization Theory and Behavior, 16(2):245-263.

[3] Brown, T.E., Davidsson, P., \& Wiklund, J. 2001. An operationalization of Stevenson's conceptualization of entrepreneurship as opportunitybased firm behavior. Strategic management journal, 22(10): 953-968.

[4] Dong, Y, Bartol, K. M., Zhang, Z. X., \& Li, C. 2017. Enhancing employee creativity via individual skill development and team knowledge sharing: Influences of dual-focused transformational leadership. Journal of Organizational Behavior, 38(3):439-458.

[5] Farmer, S. M., Tierney, P., \& Kung-McIntyre, K. 2003. Employee creativity in Taiwan: An application of role identity theory. Academy of Management Journal, 46(5):618-630.

[6] García, L. M., Deserti, A., \& Teixeira, C. 2017. Entrepreneurial design: The role of design as driver entrepreneurial opportunity generation and assessment. International Journal of Entrepreneurship and Innovation Management, 21(1-2):64-85.

[7] Jiang, W. \& Gu, Q. 2016. How abusive supervision and abusive 
supervisory climate influence salesperson creativity and sales team effectiveness in China. Management Decision, 54(2): 455-475.

[8] Miao, C., Coombs, J. E., Qian, S., \& Sirmon, D. G. 2017. The mediating role of entrepreneurial orientation: A meta-analysis of resource orchestration and cultural contingencies. Journal of Business Research, 77: 68-80.

[9] Midgley, C., Kaplan, A., \& Middleton, M. 2001. Performance-approach goals: Good for what, for whom, under what circumstances, and at what cost? Journal of Educational Psychology, 93(1): 77.

[10] Schumpeter, J. A. 2000. Entrepreneurship as Innovation. Oxford: Oxford University Press. [11]Tamer Cavusgil, S., Calantone, R. J., \& Zhao, Y. 2003. Tacit knowledge transfer and firm innovation capability. Journal of Business \& Industrial Marketing, 18(1):6-21.

[12] Trong Tuan, L. 2017. Organizational social capital as a moderator for the effect of entrepreneurial orientation on competitive intelligence. Journal of Strategic Marketing, 25(4): 301-315. 